\title{
(2) OPEN ACCESS \\ Ten-year tenure as a physician CEO at a Nordic university hospital: five lessons learnt
}

\author{
Tor Ingebrigtsen (1) 1,2,3
}

${ }^{1}$ Clinical Medicine, UiT The Arctic University of Norway, Tromso, Norway

${ }^{2}$ Neurosurgery, Ophthalmology and Otorhinolaryngology, University Hospital of North Norway, Tromso, Norway ${ }^{3}$ Australian Institute of Health Innovation, Macquarie University, Sydney, New South Wales, Australia

Correspondence to Professor Tor Ingebrigtsen, Clinical Medicine, UiT The Arctic University of Norway, Tromso 9038, Norway; tor.ingebrigtsen@unn.no

Received 17 September 2021 Accepted 1 February 2022
Check for updates

(c) Author(s) (or their employer(s)) 2022. Re-use permitted under CC BY-NC. No commercial re-use. See rights and permissions. Published by BMJ.

To cite: Ingebrigtsen T. BMJ Leader Published Online First: [please include Day Month Year]. doi:10.1136/ leader-2021-000558

\section{ABSTRACT}

Background I was a 42-year-old neurosurgeon with experience as department head when I took chair as chief executive officer (CEO) at the University Hospital of North Norway to lead a comprehensive organisational and financial restructuring. This article aims to develop lessons learnt during my 10-year tenure.

Methods I restructured the organisation and hired a new executive team. We developed a new strategy and measures to implement it. I describe the results, a strategic disagreement that developed and my resignment, and reflect critically over my actions as a leader.

Results Measures of safety and quality in clinical processes, cost-effectiveness and financial equity improved. We expedited investments in medical equipment, information technology and hospital facilities. Patient satisfaction was stable, but employees' job satisfaction decreased. After 9 years, a politicised strategic disagreement with superior authorities developed. I was criticised for attempting to influence inappropriately, and resigned.

Lessons learnt (1) Data-driven improvement works, but comes at a cost. Healthcare organisations should consider to prioritise resilience over efficiency. (2) It is inherently difficult to recognise when and how an issue changes from a professional to a political logic. I should have used contacts in politics and surveilled local media better. (3) During conflict, role clarity is crucial. (4) CEOs should be prepared to resign when strategically unaligned with superior authorities. (5) A CEO tenure should not last more than 10 years.

Conclusion My experiences as a physician CEO was intense and immensely interesting, but some of the lessons were painfully learnt.

\section{INTRODUCTION}

In August 2007, I took office as chief executive officer (CEO) at the University Hospital of North Norway (UNN), which is the northernmost in the world, and the smallest, most remote and most recently established university hospital in the country (founded 1972). By then, few Norwegian hospitals had a physician CEO, but one of the government's measures to implement the 2002 hospital reform was to strengthen professional medical leadership.

As with most physicians, I never planned for a leadership career. ${ }^{12}$ However, as a native to the region and one of the first neurosurgeons trained locally, I found myself as the department head only a year after board certification, because there was no one else to turn to. At the age of 42 years, I had 8 years of managerial experience. My predecessor and one of the country's very few physician CEOs then talked me into the job as chief medical officer with the regional health authorities, and subsequently as his successor when he retired after a record-breaking 25 -year tenure.

The leadership challenge came at a turbulent time. The goals for the 2002 hospital reform were to improve quality and tackle uncontrolled cost increase. Ownership was transferred from the counties to the state, and regional health authorities (RHAs) were established as owners. They merged hospitals into health enterprises and replaced previous boards governed by local politicians with professional enterprise boards. When I took office, the UNN had changed over a few years from a single-campus referral and teaching hospital with 3000 employees to a complex health endeavour comprising five somatic and psychiatric hospitals, seven district psychiatric and medical centres and a widely distributed air and ground ambulance system with a total of 6000 employees. ${ }^{3}$ The organisation was unaligned with diverse subcultures and the financial management was out of control, with a $10 \%$ budget deficit in 2006 .

The new board initiated a comprehensive organisational and financial restructuring, designed to forge a new and common organisational culture, improve patients' outcomes, regain financial control and raise funds for investments. They hired me to lead the change. Ten years later, I resigned after strategic disagreement with the RHA.

The aim of this article is to critically reflect over my actions as a leader, to contemplate some of the experiences based on research knowledge, and to develop lessons learnt and insights that can be useful to other physician leaders.

ORGANISATION AND FUNDING OF HEALTHCARE The main organisational features of healthcare in Norway have been unchanged since 2002. Primary care is owned and operated by local councils. Specialised care is owned by the state and organised as health enterprises under four RHAs. The minister of health appoints the boards of the RHAs, and governs them through an annual letter of allocation. The RHAs appoint the boards of the underlying enterprises.

Funding is through a single-payer universal taxbased system. The state provides $50 \%$ as a block grant and $48 \%$ based on the activity quantified through a diagnosis-related groups (DRGs)-based system. The remaining $2 \%$ is patient co-payment. Investments are financed with equity and loans from the Ministry of Health, which implies that making surpluses is a prerequisite before major investments can be approved. 


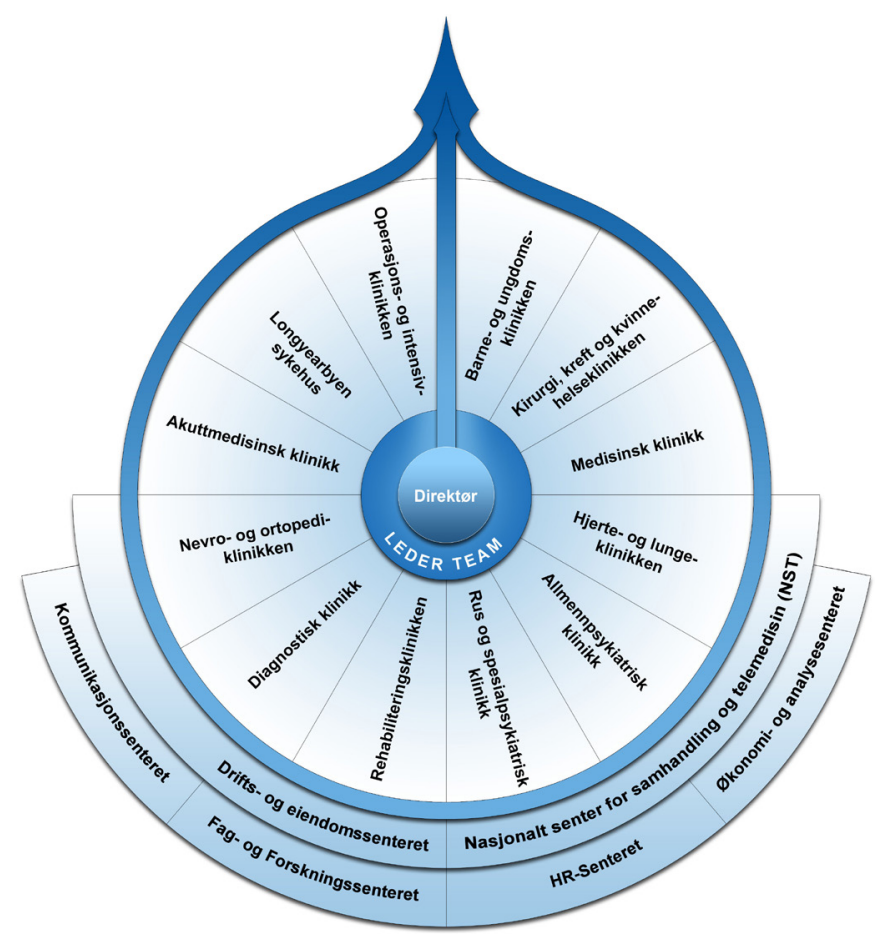

Figure 1 The executive teams understanding of its role in the organisation. The figure illustrates that the executive team aimed to understand its role as a guiding and coordinating function, embedded in the professional core of the hospital. Centre, CEO and executive team; surrounding, clinical divisions treating patients; underlying/supporting, strategic staff units. CEO, chief executive officer.

\section{ORGANISATIONAL CHANGE AND IMPROVEMENT PROGRAMME}

The change process under my leadership started out with a major organisational restructuring. After the preceding sequence of mergers, 64 diverse organisational units reported more or less directly to the CEO. This was unmanageable, and considered a root cause of the financial problems. I suggested restructuring into a divisional structure with clinical departments sharing patient pathways grouped together, as was common at the time, ${ }^{4}$ and this was approved by the board. Next, I hired mainly physicians or nurses as division directors and established the new executive team. We aimed to understand our role as a guiding and coordinating function, embedded in the professional core of the organisation (figure 1). We developed a new strategy, which was inspired by the value-based thinking of Porter and Teisberg (figure 2). ${ }^{5}$ Means to realise the strategy are listed in table 1.

\section{ASSESSMENT OF PERFORMANCE}

One of the means undertaken was to establish a comprehensive electronic leadership information system (LIS). This enabled us to gradually implement a continuously updated balanced scorecard displaying key performance indicators (KPIs).

\section{Quantitative results}

Measures of the activity, safety and quality in clinical processes generally improved. Table 2 shows selected examples. Waiting times and length of stay were reduced while the readmission rate was stable. Measures of patients' safety and outcomes also generally improved. Overall, 30-day mortality and the incidence of hospital-acquired infections declined, and survival after treatments for cancers and cardiovascular disease increased. These

\section{University Hospital of North-Norway \\ Employee participation, education,}

research, integrated care, telemedicine and culture

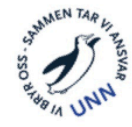

Patients' outcomes matter most!

We provide the best treatment

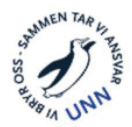

1. The UNN provides high-quality diagnostic workup, treatment and care to ensure that patients and relatives are confident and safeguarded

2. The UNN recruits highly competent employees who thrive at work

3. The UNN collaborates with UiT The Arctic University of Norway to educate highly competent health care personnel

4. The UNN is the university hospital for the Arctic region

Respect, quality, safety and care

$$
\text { HELSE } \because \text { NORO Z }
$$

Figure 2 Organisational strategy. The figure displays the organisation's name (top), strategic directions (in bold under the name), vision (in italics), main goals (numbered) and core values (bottom).

results, could, however, not be continuously assessed because national clinical quality registries published results annually. Therefore, attention both within the organisation and in the media drifted towards the process measures, and the changes tended to be perceived as efficiency only, and not quality improvement.

Table 2 also shows that the budget deficits were eliminated over 2 years followed by accounting balance or surpluses during the next 7 years. Cost-effectiveness, measured as the number of DRG points per full-time equivalent (FTE), improved. The main mechanism was that the previous continuous increase in the number of FTEs levelled off when units merged and fewer bed wards operated continuously. The financial equity balances improved, and after 5 years loans were granted. Long-awaited investments in renewal of medical equipment and information technology (eg, a joint electronic health record for our hospitals) were expedited. We planned and built a new 230-bed patient hotel, necessary to support the shift from admissions to outpatient treatments in a region with long travel distances, a positron emission tomography centre with a cyclotron, crucial to our

Table 1 Measures undertaken to implement the organisational
strategy


Table 2 Quantitative results for selected key performance indicators, years 2008-2017

\begin{tabular}{|c|c|c|c|c|c|c|c|c|c|c|}
\hline Key performance indicator & 2008 & 2009 & 2010 & 2011 & 2012 & 2013 & 2014 & 2015 & 2016 & 2017 \\
\hline \multicolumn{11}{|l|}{ Process indicators } \\
\hline Mean waiting time, somatic care (days)* & 83 & 93 & 100 & 85 & 88 & 83 & 81 & 78 & 64 & 59 \\
\hline Mean LOS, somatic care (days) & 5.8 & 5.1 & 5.1 & 5.9 & 4.8 & 4.1 & 4.1 & 4.2 & 4.3 & 4.2 \\
\hline 30-day readmission rate, elderly patients (\%) & - & - & - & - & 13.2 & 13.1 & 14.2 & 11.9 & 13.9 & 13.1 \\
\hline \multicolumn{11}{|l|}{ Patients' safety and outcomes indicators } \\
\hline 30-day survival rate after hospitalisation (\%) & - & - & 94.8 & 94.7 & 94.7 & 95.0 & 95.1 & 94.8 & 95.2 & 95.6 \\
\hline Rate of any hospital-acquired infection (\%) & - & - & - & - & 13.0 & 13.8 & 10.7 & 9.7 & 9.5 & 9.3 \\
\hline 5-year relative survival after colon cancer, women (\%) & - & 61.7 & 61.2 & 63.6 & 64.8 & 68.6 & 71.3 & 70.2 & 69.4 & 70.9 \\
\hline \multicolumn{11}{|l|}{ Financial indicators } \\
\hline Annual accounts, balance (mill. NOK) & -177 & -43 & 289 & 19 & -10 & 0 & 556 & 120 & 107 & 51 \\
\hline Number of DRG points per FTE & 8.9 & 8.4 & 9.4 & 9.8 & 9.6 & 9.9 & 10.0 & 10.1 & 10.5 & 11.0 \\
\hline Mean equity (mill. NOK) & 338 & 141 & 195 & 341 & 511 & 496 & 258 & 389 & 725 & 538 \\
\hline
\end{tabular}

- means data not available.

*Data for 2008-2010 from internal activity reports, and for 2010-2017 from the National Patient Registry.

DRG, diagnosis-related group; FTE, full-time equivalent; LOS, length of stay; NOK, Norwegian kroner.

function as the regions' cancer centre, and a new hospital wing with modern facilities for day surgery, laboratories and intensive care, during my 10-year tenure.

Measures of patient satisfaction available from national authorities' annual surveys showed stable or slightly (in some domains) improved results. In contrast, corresponding surveys of employees showed decreasing job satisfaction. Staff reported less autonomy, increased workload, more bureaucracy, inefficient internal communication, and measurement and improvement fatigue. A perception of reduced freedom to speak out was increasingly voiced, especially from the physicians' union.

\section{First lesson learnt: data-driven improvement works, but it comes at a cost}

It is well established that management using balanced scorecards can drive performance. ${ }^{6}$ This is in accordance with my experience, as I consider quantified goals and continuous measurements a central mechanism behind the change and improvement achieved. The implementation of KPIs and an electronic LIS combined with performance agreement contracts for leaders rapidly changed the organisation's focus.

I was, however, not sufficiently aware of the risks. Composition of a balanced scorecard of KPIs relevant across organisational levels and units was difficult to negotiate. Professionals struggled to agree on the selection, and few were satisfied with the compromises reached. Imbalance in data availability, especially between process and outcome measures, skewed attention away from the core of the strategy. Also, central authorities superimposed new goals and KPIs on those prioritised by us, and middle managers faced conflicting goals.

I was familiar with data-driven improvement from clinical research within neurosurgery, but not sufficiently aware of the contradictions and pitfalls of performance management in complex organisations. As a consequence, I was surprised when the organisation I thought I knew paradoxically reported reduced job satisfaction, while most KPIs showed improvements. This necessitated a comprehensive, long-lasting and resourcedemanding communication effort with middle managers, union representatives and employees. Recently, scholars addressed the high price of efficiency, and suggested organisations should offer more attention to resilience. ${ }^{78}$ This could make sense. On the other hand, building in the recommended slack in a public hospital which is restrained by not only financial resources, but also staff shortages, is difficult.

\section{STRATEGIC DISAGREEMENT AND RESIGNMENT}

After 9 years, I felt that further improvement was slow and difficult. My surgical skills had obviously eroded, and I was concerned my competencies as a clinical scientist were declining. I was considering taking advantage of an option in my contract to step down and extend my university affiliation to a full-time professorship. DeVries divided CEO tenures in an entry phase characterised by learning and innovation, a consolidation phase where key stakeholders and executives are committed to the chosen strategy and changes are implemented, and a decline phase in which stagnation occurs. ${ }^{9}$ I was concerned my leadership was stagnating.

In parallel, a disagreement over the organisation of percutaneous coronary intervention (PCI) emerged. A working group appointed by the RHA had considered decentralisation to a satellite unit at the second largest hospital in the region, but could not agree. Our hospital's members strongly discouraged the idea, with references to excellent patient outcomes (survival rates $>90 \%$ for acute myocardial infarction (MI) and no geographical variation). They feared fragmentation and reduced quality of care. In contrast, physicians at the other hospital claimed patients had almost died during interhospital transfers. They collaborated with local media editors and politicians, and launched a campaign advocating the decentralisation. My executive team perceived a strategic shift threatening our mission as a fully specialised university hospital serving North Norway's confined rural population of only 480000 inhabitants. Our board unconditionally supported this view. After a year with politicised turmoil, the RHA's board voted for the decentralisation. I was criticised for attempting to influence inappropriately, and I felt I had no option but to resign. The head and deputy head of the UNN board were replaced.

\section{Second lesson learnt: it is inherently difficult to recognise when and how an issue changes from a professional to a political logic}

Within the UNN, we presupposed the study of how PCI should be organised would follow the usual professional logic. We expected that registry data about patients' outcomes and the absence of geographical variation would be decisive, and did not sense what was under discussion among politicians and in local media in the southern part of the region. We were taken by surprise when 18 mayors campaigned for the decentralisation, arguing that one of them had almost died from an acute MI during air ambulance transfer to the UNN. The groundless contention that patients residing in the 
southern part of the region had inferior outcomes after acute MI had become 'common knowledge' before we became aware of the situation. Politicians in our part of the region slowly mobilised to preserve what they perceived to be a high-quality service, only to escalate the conflict.

Geographically based conflicting interests should be of no surprise to healthcare leaders. I knew this, but nonetheless learnt that it is inherently difficult to recognise when and how the discourse of a process changes from a professional to a political logic. In hindsight, the board could have used their political network better to retrieve information at an earlier stage, and as the tertiary referral hospital for the entire region, we should obviously have surveilled all local media more rigorously.

\section{Third lesson learnt: during conflict, role clarity is crucial}

The head of UNN board and I agreed that I should communicate directly with the RHA and its board, since we perceived the issue to be mainly of medical professional character. This was in accordance with previous practice, but unruly in the specific situation, as it is the head of the enterprise board (and not the CEO) who reports to the board at the superior regional level. This lack of role clarity shifted attention away from the issue under debate to procedural formalities. This weakened our case and caused the abrupt breakdown of trust and change of leadership.

Fourth lesson learnt: be prepared to resign when strategically unaligned with superior authorities

In hindsight, it gradually became clear over a period of months that a disagreement about strategic direction had developed between the UNN and the RHA. I was not sufficiently conscious of my own attitude, and in consequence, not transparent regarding my intentions. I hoped they would bend, and return to a professional logic.

I never made it clear that I was not willing to lead what I perceived as dismantling of a core function in the university hospital. I was afraid that stating this would be understood as an inappropriate 'threat to resign'. Research shows, however, that hospitals whose leaders are strategically unaligned with superior authorities, stagnate. ${ }^{10}$ Therefore, it would have been frank to make my position clear. It complicated matters that our board, who I reported to, followed the same path. I should, in any case, have understood that a board strategically unaligned with the superior authority who appoints it, would be replaced.

Paradoxically, our organisation came together during this process. Both I as the CEO and the board experienced unconditional support. The internal tensions described above faded, and employees applauded a leadership that stood up for the organisation's values and strategy. This is of course a well-known phenomenon when facing a 'common enemy'. It strengthened my aftermath, but obviously caused a weakening of the confidence and collaboration in the region.

\section{Fifth lesson learnt: 10 years is enough!}

As mentioned, I was considering resigning when the situation that prompted my resignation emerged. Evidence from studies of commercial industries shows an inverted U-shaped relationship between CEO tenure and profitability, ${ }^{11}$ and studies of hospitals indicate that frequent CEO churns impact quality systems negatively. ${ }^{12}$ Taken together, continuity in leadership is favourable, but the risk of stagnation is high after 10 years. It is probably time to step down for a CEO once one has started considering it. I think I inexpediently postponed the decision because I wanted to experience some of the milestones to be reached, such as celebrating the opening of new facilities.
Finally, should I have accepted the CEO challenge in the first place? By then, I believed it was important that hospitals were led by doctors. Recent studies report an association between physician CEOs, better treatment outcomes and higher patient satisfaction. ${ }^{1314}$ Cross-sectional comparisons are, however, prone to selection bias: it is difficult to know whether good hospitals recruit physician CEOs easier, or whether such CEOs actually change their hospitals for the better.

\section{CONCLUSION}

The 10-year tenure as a physician CEO was an intense and immensely interesting experience. I believe my background as a clinician and professor influenced the organisations' prioritisations and contributed to improved outcomes for patients during a period in which developments were otherwise framed by general trends in healthcare and politics. Some lessons were painfully learnt, though.

\section{Twitter Tor Ingebrigtsen @IngebrigtsenTor}

Acknowledgements The author thanks analyst Thomas Krogh and graphic designer Frode Abrahamsen at the UNN for help with providing the quantitative data and designing the figures, respectively. Deputy CEO Marit Lind, head of research and education Einar Bugge and CMO Haakon Lindekleiv at the UNN, and research assistant Kelly Nguyen and Professor Jeffrey Braithwaite at the Australian Institute of Health Innovation, provided invaluable help with critically reviewing the manuscript.

Contributors I am the only author of this manuscript.

Funding The author have not declared a specific grant for this research from any funding agency in the public, commercial or not-for-profit sectors.

Competing interests None declared.

\section{Patient consent for publication Not required.}

Provenance and peer review Not commissioned; externally peer reviewed.

Open access This is an open access article distributed in accordance with the Creative Commons Attribution Non Commercial (CC BY-NC 4.0) license, which permits others to distribute, remix, adapt, build upon this work non-commercially, and license their derivative works on different terms, provided the original work is properly cited, appropriate credit is given, any changes made indicated, and the use is non-commercial. See: http://creativecommons.org/licenses/by-nc/4.0/.

\section{ORCID iD}

Tor Ingebrigtsen http://orcid.org/0000-0001-5966-9786

\section{REFERENCES}

1 Ham C, Clark J, Spurgeon P, et al. Doctors who become chief executives in the NHS: from keen amateurs to skilled professionals. J R Soc Med 2011;104:113-9.

2 Thornton J. "Doctors need to step up" —why are there still so few medical chief executives in the NHS? BMJ 2019;365:14341.

3 Ingebrigtsen T, Lind M, Krogh T, et al. Merging of three hospitals into one university hospital. Tidsskr Nor Laegeforen 2012;132:813-7.

4 Lega F, DePietro C. Converging patterns in hospital organization: beyond the professional bureaucracy. Health Policy 2005;74:261-81.

5 Porter ME, Teisberg EO. Redefining health care. Boston, MA: Harvard Business School Press, 2006.

6 Kaplan RS, Norton DP. The balanced scorecard: measures that drive performance. Harv Bus Rev 2005;83:172-80.

7 Martin RL. The high price of efficiency. Harv Bus Rev 2019;97:43-55.

8 Braithwaite J, Wears RL, Hollnagel E. Resilient health care: turning patient safety on its head. Int J Qual Health Care 2015;27:418-20.

9 DeVries MFRK. When it's time for the CEO to go. Harv Bus Rev, 2014. Available: https://hbr.org/2014/03/when-its-time-for-the-ceo-to-go [Accessed 17 Sep 2021].

10 Denis J-L, Lamothe L, Langley A. The dynamics of collective leadership and strategic change in pluralistic organizations. Academ Man J 2001;44:809-37.

11 Henderson AD, Miller D, Hambrick DC. How quickly do CEOs become obsolete? industry dynamism, CEO tenure, and company performance. Strateg Manag J 2006;27:447-60

12 Leggat S, Balding C. The impact of leadership churn on quality management in Australian hospitals. J Health Organ Manag 2019;33:809-20.

13 Clay-Williams R, Ludlow K, Testa L, et al. Medical leadership, a systematic narrative review: do hospitals and healthcare organisations perform better when led by doctors? BMJ Open 2017;7:e014474.

14 Kaiser F, Schmid A, Schlüchtermann J. Physician-Leaders and hospital performance revisited. Soc Sci Med 2020;249:112831. 